\title{
Impact on radiation dose and volume V57 Gy of the brain on recurrence and survival of patients with glioblastoma multiformae
}

\author{
Igor Stojkovski, Valentina Krstevska, Snezhana Smichkoska \\ University Clinic of Radiotherapy and Oncology, Skopje, Macedonia \\ Radiol Oncol 2017; 51(4): 463-468. \\ Received 11 June 2017 \\ Accepted 11 September 2017 \\ Correspondence to: Igor Stojkovski, University Clinic of Radiotherapy and Oncology - Skopje, Majka Tereza (Vodnjanska) 17, \\ 1000 Skopje, Macedonia. Phone: +389 7639 7454; Fax: +389 2311 1430; E-mail: istojkovski@gmail.com \\ Disclosure: No potential conflicts of interest were disclosed.
}

Background. The aim of the study was to analyze impact of irradiated brain volume V57 Gy (volume receiving 57 Gy and more) on time to progression and survival of patients with glioblastoma.

Patients and methods. Dosimetric analysis of treatment plan data has been performed on 70 patients with glioblastoma, treated with postoperative radiochemotherapy with temozolomide, followed by adjuvant temozolomide. Patients were treated with 2 different methods of definition of treatment volumes and prescription of radiation dose. First group of patients has been treated with one treatment volume receiving $60 \mathrm{~Gy}$ in $2 \mathrm{~Gy}$ daily fraction (31 patients) and second group of the patients has been treated with "cone-down" technique, which consisted of two phases of treatment: the first phase of $46 \mathrm{~Gy}$ in $2 \mathrm{~Gy}$ fraction followed by "cone-down" boost of $14 \mathrm{~Gy}$ in $2 \mathrm{~Gy}$ fraction 39 patients). Quantification of V57 Gy and ratio brain volume/V57Gy has been done. Average values of both parameters have been taken as a threshold value and patients have been split into 2 groups for each parameter (values smaller/ lager than threshold value).

Results. Mean value for V57 Gy was $593.39 \mathrm{~cm}^{3}$ (range 166.94 to $968.60 \mathrm{~cm}^{3}$ ), mean value of brain volume has was $1332.86 \mathrm{~cm}^{3}$ (range 1047.00 to $1671.90 \mathrm{~cm}^{3}$ ) and mean value of brain-to-V57Gy ratio was 2.46 (range 1.42 to 7.67). There was no significant difference between two groups for both $\vee 57 \mathrm{~Gy}$ and ratio between brain volume and V57 Gy.

Conclusions. Irradiated volume with dose 57 Gy or more (V57 Gy) and ration between whole brain volume and 57 Gy had no impact on time to progression and survival of patients with glioblastoma.

Key words: irradiation V57; glioblastoma

\section{Introduction}

Glioblastoma is most common and most aggressive brain tumor with incidence of 2-3 per 100000 population according to GLOBOCAN. ${ }^{1}$ Incidence of glioblastoma accounts $12-15 \%$ of all intracranial tumors and approximately 50-60 of all astrocytic tumors. ${ }^{2,3}$ Diagnosis, treatment and follow up of patients with glioblastoma and multidisciplinary approach and best results are achieved in specialized centers, which can offer all treatment modalities when it is needed and which are more experienced with larger volume of cases. ${ }^{4}$ Mutual understanding and collaboration of team of professionals is of paramount importance for obtaining best medical care and best clinical results (tumor control and survival). During last two decades, major advantages have been made in enhancing precision of radiation treatment and shaping of radiation dose to increase dose distribution in target and to decrease radiation dose in organs at risk. Three-dimensional conformal radiotherapy and its derivates, Intensity Modulated Radiation Therapy (IMRT) and Volumetric Arc Therapy (VMAT) are 
now standard of treatment for patients with glioblastoma. ${ }^{5-7}$ Standard postoperative treatment of patients with glioblastoma consist of postoperative radiotherapy with temozolomide followed by adjuvant temozolomide. ${ }^{8-11}$ Radiotherapy is corner-stone of multimodality approach and it is considered as treatment with highest benefit of all three treatment modalities. Despite the major advantages in personalization and precision of the radiotherapy treatment, median survival of patients with glioblastoma is still between 12 and 16 months from diagnosis. ${ }^{4}$

In general there are two major approaches in definition of gross tumor volume (GTV) in patients with glioblastoma. In studies conducted by EORTC (European Organization for Research and Treatment of Cancer) only one contoured gross tumor volume is used which is defined as an enhanced visible tumor on MR images prior the surgery expanded respectively to clinical target volume (CTV) and planning target volume (PTV) according ESTRO-ACROP Guidelines. ${ }^{7}$

In contrast in studies conducted by RTOG (Radiation Therapy Oncology Group) definition of volumes in according to "cone-down" approach, which means that there are virtually two volumes defined on preoperative and/or postoperative $\mathrm{MR}$, one initial (larger) volume and second "conedown" volume or boost volume (smaller). With "cone-down" approach in some clinical situation it is possible do decrease radiation dose to the brain which could have impact on survivorship of patients with glioblastoma. ${ }^{12,13}$

Volume of the tumor measured as initial tumor size or preoperative tumor size and residual disease is generally considered as a prognostic factor for survival and recurrence in patients with glioblastoma. ${ }^{14,15}$ There are various approaches and quantification of what is really visible tumor and

TABLE 1. Patient characteristics

\begin{tabular}{|c|c|c|}
\hline & $\begin{array}{l}\text { Group } 1(1 \mathrm{v}) \\
31 \text { patients }\end{array}$ & $\begin{array}{l}\text { Group } 2 \text { (cone-down) } \\
39 \text { patients }\end{array}$ \\
\hline Age & $\begin{array}{l}\text { Range 29-71, median } \\
\text { age } 56\end{array}$ & $\begin{array}{l}\text { Range } 27-75 \text {, median } \\
\text { age } 56\end{array}$ \\
\hline Sex & $\begin{array}{l}\text { Male - } 14 \\
\text { Female - } 17\end{array}$ & $\begin{array}{l}\text { Male - } 21 \\
\text { Female - } 18\end{array}$ \\
\hline $\begin{array}{l}\text { Location of the } \\
\text { primary lesion }\end{array}$ & $\begin{array}{l}5 \text { - frontal lobe } \\
6 \text { - temporal lobe } \\
11 \text { - parietal lobe } \\
2 \text { - occipital lobe } \\
7 \text { - overlapping }\end{array}$ & $\begin{array}{l}8 \text { - frontal lobe } \\
15 \text { - temporal lobe } \\
9 \text { - parietal lobe } \\
1 \text { - occipital lobe } \\
6 \text { - overlapping }\end{array}$ \\
\hline $\begin{array}{l}\text { Average time from } \\
\text { surgery to RT (days) }\end{array}$ & $36(25-55)$ & 39 (24-74) \\
\hline V57 Gy & $\begin{array}{l}<600 \mathrm{~cm}^{3}-15 \\
>600 \mathrm{~cm}^{3}-16\end{array}$ & $\begin{array}{l}<600 \mathrm{~cm}^{3}-23 \\
>600 \mathrm{~cm}^{3}-16\end{array}$ \\
\hline
\end{tabular}

consequently, what volume should be irradiated in order to minimize tumor recurrence, but reaching consensus between different research groups is still under debate. Definition of volume of the tumor, depends of imaging modality used, resolution of imaging modality, processing algorithms and various other variables. ${ }^{15-18}$

After definition of gross tumor volume there is still debate, what is most appropriate clinical treatment volume (CTV). There are different approaches, which are evolving together with advances of imaging. CTV as concept in glioblastoma is difficult to define and different research groups have various definitions and no-one of these definitions is absolutely true or false..$^{20-28}$

There are more or less well defined criteria for definition of CTV and PTV for patients with glioblastoma specially treated in clinical trial setting, as AVAGlio and Centric trials, recently. ${ }^{28,29}$

Also it is well known fact that in daily clinical practice clinicians are adopting volume delineation according to their clinical setting and capabilities, and using delineation according to RTOG, EORTC or institutional standards. ${ }^{30}$

In our study we treated patients with two different approaches on delineation on treatment volumes using one phase treatment EORTC "like" and RTOG "like" approach, but randomization was used for assignment of patients in the group as a part of the standard protocol for treatment developed in the institution.

\section{Patients and methods}

This study was approved by the ethical committee of Medical Faculty at University "Ss. Cyril and Methodius" in Skopje and University Clinic of Radiotherapy and Oncology in Skopje (Number: 03-2455/2) and was carried out according to the Declaration of Helsinki.

Total of 70 patients, with glioblastoma multiforme has been included in this study. Patient accrual has been performed in the period from January 2013 to December 2015. All patients have been previously surgically treated with maximal safe resection of the primary tumor and definitive histological diagnosis has been established as a glioblastoma multiforme according to the last World Health Organization classification. ${ }^{3}$

After referral to radiotherapy treatment, patients have been scheduled for computed tomography $(\mathrm{CT})$ simulation in treatment position. CT scan has encompassed cranial region according to 
institutional protocol with slice thickness of $2 \mathrm{~mm}$. For immobilization purpose thermoplastics masks and head rests have been used during simulation and treatment.

After computed tomography simulation, image fusion with preoperative and/or postoperative MR scan has been done using automatic MR-CT fusion using non deformable algorithm with manual correction, only if necessary, leaded by decision of radiation oncologist. MR-CT fusion has been done using transversal MR images using T1 with contrast and T2/FLAIR sequence. In the analysis has been included only patents who finished complete treatment, total of 70 patients from included 78 patients. Eight patients did not finish treatment, and were excluded from analysis.

Patients have been randomly assigned to one of the groups on the basis of referral to the department. Patients with odd hospital number have been assigned to the first group, and patients with even hospital number have been assigned to second group. In the first group of the patients (total of 31 patients), delineation was based on T2/FLAIR and T1 with contrast enhancements and only one GTV volume has been contoured. After delineation of GTV, CTV was expanded for $2 \mathrm{~cm}$, taking in account anatomic boundaries and omitting, if possible, organs at risk. CTV was expanded to PTV with addition of margin of $5 \mathrm{~mm}$, which is considered institutional standard. In the second group (total of 39 patients), "cone-down" approach has been used and delineation of target volume has been done in two phases and two GTV volumes have been delineated. First or initial volume GTV46, has been delineated based on MR images using T2/FLAIR abnormalities. Expansion of GTV to CTV has been done with margin of $2 \mathrm{~cm}$, taking in account anatomic boundaries and avoidance of organs at risk, similar as in first group. Further expansion of CTV to PTV was with margin of $5 \mathrm{~mm}$. Cone down volume or boost volume has been delineated on contrasts enhanced T1 MR Image set. CTV has been expanded for $2 \mathrm{~cm}$, and PTV expanded further for $0.5 \mathrm{~cm}$, as initial delineated volume.

Dose prescription for patients in the first group was 60 Gy in 30 daily fractions of 2 Gy and in second group, prescribed dose for initial volume was $46 \mathrm{~Gy}$ in 23 fractions and for the "cone-down" volume additional $14 \mathrm{~Gy}$ in 7 fractions. Initial and "cone-down" volumes have been treated with 2 Gy daily fractions. Treatment schedules for both groups were 5 fractions on each consecutive day in 7 days week.
Treatment planning has been done using Varian Eclipse planning system version 10.0.45.0 and the most appropriate treatment plan have been selected in order to achieve dose distribution in target(s) and in organs at risk in order to fulfill QUANTEC criteria. ${ }^{31-33}$

Together with radiotherapy all patients were treated according to "Stupp protocol" and received concurrent chemotherapy with temozolomide, followed by adjuvant temozolomide. ${ }^{35}$

After treatment, patients undergo follow up which consisted of physical examination every month which corresponded with adjuvant chemotherapy cycle, MR every 3-4 months and other clinical examination if necessary. Follow up strategy was in line with ESMO clinical recommendations and modified according to specific clinical situation. ${ }^{9}$

Two volumetric parameters were selected as relevant in order to predict exposure to brain as an organ at risk in our series of patients. First parameter is volume which received $57 \mathrm{~Gy}$ and more in $\mathrm{cm}^{3}$, "V57Gy", and second parameter is calculated as a ratio between brain volume and "V57Gy", calculated as numeric coefficient, decimal number.

"V57Gy" was calculated using TPS software and using build in algorithms for converting isodose level to structure. This function is standard in majority of modern treatment planning systems available in the market and it is available as a standard option in our institutional TPS.

Patients has been separated in 2 groups for both parameters and threshold values were estimated for "V57Gy" equal to $600 \mathrm{~cm}^{3}$ and for ratio between brain volume and "V57Gy" equal to 2.4 presented as a decimal number.

Based on the first parameter, patents were split on 2 groups. The first group of patients with "V57Gy" up to $600 \mathrm{~cm}^{3}$ consisted of 38 patients, and second group of patients with "V57Gy" more than $600 \mathrm{~cm}^{3}$ consisted of 32 patients.

According to second parameter, ratio between brain volume and "V57Gy", patients were also split into 2 groups: patients with ratio less than 2.4 numeric value (40 patients) and patients with ratio of more than 2.4 (30 patients).

\section{Results}

Median follow up of all 70 patients was 12 months (range from 4 to 33 months). Median time to progression (recurrence) was 12 months and median 


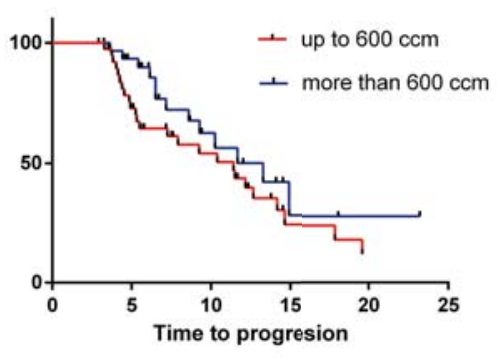

FIGURE 1. Time to progression for "V57Gy" volume. Threshold value was $600 \mathrm{~cm}^{3}$.

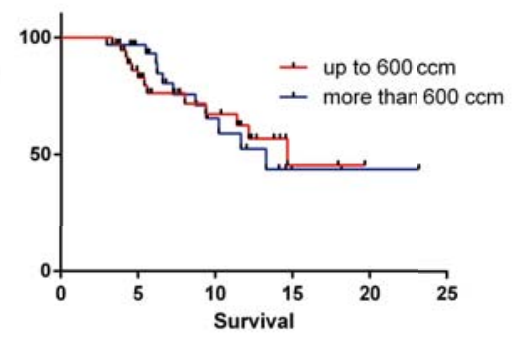

FIGURE 2. Overall survival for "V57Gy" volume. Threshold value was $600 \mathrm{~cm}^{3}$.

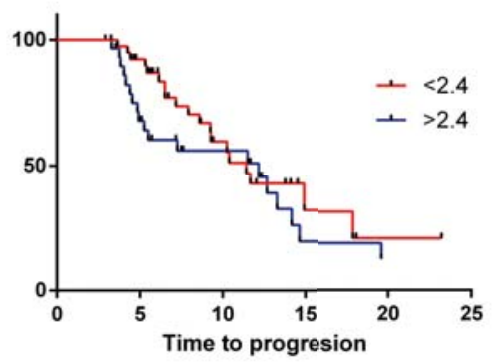

FIGURE 3. Time to progression for ration between brain volume and "V57Gy" volume. Threshold value was 2.4 .

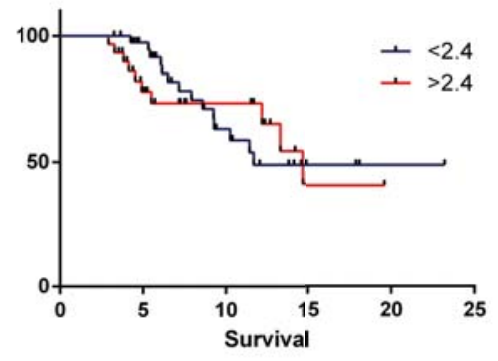

FIGURE 4. Overall survival for ration between brain volume and "V57Gy" volume. Threshold value was 2.4 .

survival was calculated as 24 months using Kaplan Meir method. ${ }^{35}$

Survival analysis using Kaplan Meir method has been done on two parameters for both time to progression (recurrence) and overall survival. Comparison of survival has been calculated using Matel-Cox and Gehan-Breslow-Wilcoxon (logrank) tests. ${ }^{36,37}$

For volumetric parameter of "V57Gy", comparison of patients with "V57 Gy" of less than $600 \mathrm{~cm}^{3}$ (38 patients) and more than $600 \mathrm{~cm}^{3}$ (32 patients) has been done. Time to progression for group of patients with "V57Gy" $\leq 600 \mathrm{~cm}^{3}$ was 11.43 months and for group of patients with "V57Gy" $>600 \mathrm{~cm}^{3}$ was 13.29 and for overall survival, 14.64 and 13.29 months. (Figure 1,2). There was not any significant difference for both time to progression $(p=0.2065)$ and overall survival $(p=0.9970)$.

For second parameter, calculated as numeric value, ration between whole brain volume and "V57Gy" volume, comparison for time to progression and overall survival for patients with numerical value $\leq 2.4$ (40 patients) and numeric value $>2.4$ (30 patients) has been done. Median time to progression for group of patients with value $\leq 2.4$ was 11.43 months and for group of patients with numeric value $>2.4$ was 12.18 months. Overall surviv-

al was 11.68 and 14.64 months respectively. There was no significant difference in time to progression $(p=0.2881)$ and overall survival $(p=0.8572)$ between this two groups (Figure 3, 4).

\section{Discussion}

Based on this data we concluded that these volumetric parameters did not have any impact on time to progression and overall survival on patients with glioblastoma, treated with postoperative radiochemotherapy. In general, in malignant tumors, size of the tumor is considered as an independent prognostic factor which is described as a $\mathrm{T}$ stage according to UICC Classification ${ }^{38}$, but due to specific characteristics of brain tumors, TNM classification for prognostic values is not applicable, but rather WHO classification which do not correspond to size of the tumor. According to EORTC and NCIC nomogram for predicting outcome in patients with newly diagnosed glioblastoma, there are several factors which are predicting survival. Following parameters are suggested as potential prognostic factors, which should be reported in all clinical studies: MGMT promoter methylation status, age, performance status, extent of resection, and Mini Mental State Examination (MMSE). ${ }^{39}$

Volumetric parameters calculated in our study did not have impact on local control and overall survival. In our study threshold value was estimated as an average value from our series of the patients. In the future studies we are planning to include more patients for evaluation of volumetric parameters and to create more strict constraints with higher gradient. In this case we had approximation that there will be difference in both recurrence and survival for patients with smaller irradiated volumes compared with very large irradiated volume, which should be proven in future studies.

Radiation treatment of CNS tumors has been evolved in the past two decades with introduction of more precise imaging and treatment devices in radiation oncology followed by development of more precise treatment techniques. Despite the fact that modern treatment devices are able to deliver higher dose to specified tumor volume, using possibility to conform beams in order to protect critical organs there, are not positive studies to prove that escalation of radiation dose beyond $60 \mathrm{~Gy}$ with standard fractionation will have impact of the disease control. ${ }^{40}$ There are some exceptions regarding dose and fractionation for patients with poor performance status. Recent studies showed that 
shortening duration of radiotherapy treatment with increasing daily fraction (40 Gy in 15 fractions or $25 \mathrm{~Gy}$ in 5 fractions) is with equivalent results regarding survival and quality of life. ${ }^{42}$ In our study we showed that decreasing of treated volume with cone-down approach did not have any impact on marginal recurrence in glioblastoma patients treated with radiotherapy and concurrent and adjuvant temozolomide. These results are in line with recent published studies that reducing treated volume with careful delineation of visible tumor on MR, will not have any impact on marginal recurrence. ${ }^{42-45}$

Finally, careful selection of imaging modalities, registration and selection of the most suitable treatment plan is of paramount importance for obtaining best results and obtaining best local control during radiation treatment of patients with glioblastoma.

\section{References}

1. Ferlay J, Soerjomataram I, Dikshit R, Eser S, Mathers C, Rebelo M, et al. Cancer incidence and mortality worldwide: sources, methods and major patterns in GLOBOCAN 2012. Int J Cancer 2015; 136: E359-86. doi: 10.1002/ ijc. 29210

2. Louis DN, Ohgaki H, Wiestler OD, Cavenee WK, Burger PC, Jouvet A, et al. The 2007 WHO classification of tumours of the central nervous system. Acta Neuropathol 2007; 114: 97-109. doi: 10.1007/s00401-007-0243-4

3. Louis DN, Perry A, Reifenberger G, von Deimling A, Figarella-Branger D, Cavenee WK, et al. The 2016 World Health Organization classification of tumors of the central nervous system: a summary. Acta Neuropathol 2016; 131: 803-20. doi: 10.1007/s00401-016-1545-1

4. Thumma SR, Fairbanks RK, Lamoreaux WT, Mackay AR, Demakas JJ, Cooke $\mathrm{BS}$, et al. Effect of pretreatment clinical factors on overall survival in glioblastoma multiforme: a Surveillance Epidemiology and End Results (SEER) population analysis. World J Surg Oncol 2012; 10: 75. doi: 10.1186/14777819-10-75

5. Belkacemi Y, Bolle S, Bourdeaut F, Collin P, Cornu P, Delatre JY, et al. Guidelines, 'minimal requirements' and standard of care in glioblastoma around the Mediterranean Area: A report from the AROME (Association of Radiotherapy and Oncology of the Mediterranean arEa) Neuro-Oncology working party. Crit Rev Oncol Hematol 2016; 98: 189-99. doi: 10.1016/j. critrevonc.2015.10.014

6. Mason WP, Maestro RD, Eisenstat D, Forsyth P, Fulton D, Laperriere N, et al. Canadian recommendations for the treatment of glioblastoma multiforme. Curr Oncol 2007; 14: 110-7. doi: http://dx.doi.org/10.3747/co.2007.119

7. Niyazi M, Brada M, Chalmers AJ, Combs SE, Erridge SC, Fiorentino A, et al. ESTRO-ACROP guideline 'target delineation of glioblastomas'. Radiother Oncol 2016; 118: 35-42. doi: 10.1016/j.radonc.2015.12.003

8. Stupp R, Tonn JC, Brada M, Pentheroudakis G. High-grade malignant glioma: ESMO clinical practice guidelines for diagnosis, treatment and follow-up. Ann Oncol 2010; 21(Suppl. 5): 190-3. doi: 10.1093/annonc/mdq187

9. Stupp R, Brada M, van den Bent MJ, Tonn JC, Pentheroudakis G. High-grade glioma: ESMO clinical practice guidelines for diagnosis, treatment and follow-up. Ann Oncol 2014; 25: 93-101. doi: 10.1093/annonc/mdu050

10. Weller M, van den Bent M, Hopkins K, Tonn JC, Stupp R, Falini A, et al. EANO guideline for the diagnosis and treatment of anaplastic gliomas and glioblastoma. Lancet Oncol 2014; 15: e395-403. doi: 10.1016/S14702045(14)70011-7
11. National Comprehensive Cancer Network. Central Nervous System Cancers (Version I.2016). [cited 15 May 2017 ]. Available at: https://www.nccn.org/ professionals/physician_gls/pdf/cns.pdf.

12. Kazda T, Jancalek R, Pospisil P, Sevela O, Prochazka T, Vrzal M, et al. Why and how to spare the hippocampus during brain radiotherapy: the developing role of hippocampal avoidance in cranial radiotherapy. Radiat Oncol 2014; 9: 139. doi: 10.1186/1748-717X-9-139

13. Conson M, Cella L, Pacelli R, Comerci M, Liuzzi R, Salvatore $M$, et al. Automated delineation of brain structures in patients undergoing radiotherapy for primary brain tumors: From atlas to dose-volume histograms. Radiother Oncol 2014; 112: 326-31. doi: 10.1016/j.radonc.2014.06.006

14. Grabowski MM, Recinos PF, Nowacki AS, Schroeder JL, Angelov L, Barnett $\mathrm{GH}$, et al. Residual tumor volume versus extent of resection: predictors of survival after surgery for glioblastoma. J Neurosurg 2014; 121: 1115-23. doi: 10.3171/2014.7.JNS132449

15. Pessina F, Navarria P, Cozzi L, Tomatis S, Riva M, Ascolese AM, et al. Role of surgical resection in recurrent glioblastoma: prognostic factors and outcome evaluation in an observational study. J Neurooncol 2016; 131: 1-8. doi: 10.1007/s11060-016-2310-y

16. Feng Y, Clayton EH, Okamoto RJ, Engelbach J, Bayly P V, Garbow JR. A longitudinal magnetic resonance elastography study of murine brain tumors following radiation therapy. Phys Med Biol 2016; 61: 6121-31. doi: 10.1088/0031-9155/61/16/6121

17. Molina D, Pérez-Beteta J, Martínez-González A, Sepúlveda JM, Peralta S, Gil-Gil MJ, et al. Geometrical measures obtained from pretreatment postcontrast T1 weighted MRIs predict survival benefits from bevacizumab in glioblastoma patients. PLoS One 2016; 11: e0161484. doi: 10.1371/journal. pone.0161484

18. Sreenivasan S, Madhugiri V, Sasidharan G, Kumar RR. Measuring glioma volumes: A comparison of linear measurement based formulae with the manual image segmentation technique. J Cancer Res Ther 2016; 12: 161. doi: 10.4103/0973-1482.153999

19. Moghaddasi L, Bezak E, Harriss-Phillips W. Evaluation of current clinical target volume definitions for glioblastoma using cell-based dosimetry stochastic methods. Br J Radiol 2015; 88: 1-14. doi: 10.1259/bjr.20150155

20. Chang EL, Akyurek S, Avalos T, Rebueno N, Spicer C, Garcia J, et al. Evaluation of peritumoral edema in the delineation of radiotherapy clinical target volumes for glioblastoma. Int J Radiat Oncol Biol Phys 2007; 68: 144-50. doi: http://dx.doi.org/10.1016/j.ijrobp.2006.12.009

21. Aydin $\mathrm{H}$, Sillenberg I, von Lieven $\mathrm{H}$. Patterns of failure following CT-based 3-D irradiation for malignant glioma. Strahlenther Onkol 2001; 177: 424-31.

22. Bagri PK, Kapoor A, Singh D, Singhal MK, Narayan S, Kumar HS. Addition of magnetic resonance imaging to computed tomography-based threedimensional conformal radiotherapy planning for postoperative treatment of astrocytomas: Changes in tumor volume and isocenter shift. South Asian J cancer 2015; 4: 18-20. doi: 10.4103/2278-330X.149939

23. Hess CF, Schaaf JC, Kortmann RD, Schabet M, Bamberg M. Malignant glioma: patterns of failure following individually tailored limited volume irradiation. Radiother Oncol 1994; 30: 146-9. doi: http://dx.doi.org/10.1016/01678140(94)90044-2

24. Easaw JC, Mason WP, Perry J, Laperrière N, Eisenstat DD, Del Maestro R, et al. Canadian recommendations for the treatment of recurrent or progressive glioblastoma multiforme. Curr Oncol 2011; 18: e126-36.

25. Wallner KE, Galicich JH, Krol G, Arbit E, Malkin MG, Concannon JP, et al. Patterns of failure following treatment for glioblastoma multiforme and anaplastic astrocytoma. Int J Radiat Oncol Biol Phys 1989; 16: 1405-9. doi: http://dx.doi.org/10.1016/0360-3016(89)90941-3

26. Halperin EC, Bentel G, Heinz ER, Burger PC. Radiation therapy treatment planning in supratentorial glioblastoma multiforme: an analysis based on post mortem topographic anatomy with CT correlations. Int J Radiat Oncol Biol Phys 1989; 17: 1347-50. doi: http://dx.doi.org/10.1016/03603016(89)90548-8

27. Burger PC, Heinz ER, Shibata T, Kleihues P. Topographic anatomy and CT correlations in the untreated glioblastoma multiforme. J Neurosurg 1988; 68: 698-704. doi: 10.3171\%2Fjns.1988.68.5.0698

28. Chinot OL, Wick W, Mason W, Henriksson R, Saran F, Nishikawa R, et al. Bevacizumab plus radiotherapy-temozolomide for newly diagnosed glioblastoma. N Engl J Med 2014; 370: 709-22. doi: 10.1056/NEJMoa1308345 
29. Stupp R, Hegi ME, Gorlia T, Erridge SC, Perry J, Hong Y-K, et al. Cilengitide combined with standard treatment for patients with newly diagnosed glioblastoma with methylated MGMT promoter (CENTRIC EORTC 26071-22072 study): a multicentre, randomised, open-label, phase 3 trial. Lancet Oncol 2014; 15: 1100-8. doi: 10.1016/S1470-2045(14)70379-1

30. Ghose A, Lim G, Husain S. Treatment for glioblastoma multiforme: current guidelines and Canadian practice. Curr Oncol 2010; 17: 52-8. doi: 10.3747/ co.v17i6.574

31. Lawrence YR, Li XA, el Naqa I, Hahn CA, Lawrence BM, Merchant TE, et al. QUANTEC: Radiation dse - volume effects in the brain. Int J Radiat Oncol 2010; 76: S77-85. doi: 10.1016/j.jijobp.2009.02.091

32. Mayo C, Yorke E, Merchant TE. Radiation associated brainstem injury Int J Radiat Oncol Biol Phys 2010; 76(3 Suppl): 36-41. doi: 10.1016/j. ijrobp.2009.08.078

33. Mayo C, Martel MK, Marks LB, Flickinger J, Nam J, Kirkpatrick J. Radiation dose-volume effects of optic nerves and chiasm. Int J Radiat Oncol Biol Phys 2010; 76(3 Suppl): 28-35. doi: 10.1016/j.ijrobp.2009.07.1753

34. Stupp R, Dietrich PY, Kraljevic SO, Pica A, Maillard I, Maeder P, et al. Promising survival for patients with newly diagnosed glioblastoma multiforme treated with concomitant radiation plus temozolomide followed by adjuvant temozolomide. J Clin Oncol 2002; 20: 1375-82. doi: 10.1200/ JCO.2002.20.5.1375

35. Kaplan EL, Meier P. Nonparametric estimation from incomplete observations. J Am Stat Assoc 1958; 53: 457-81. doi: 10.2307/2281868

36. Berty HP, Shi H, Lyons-Weiler J. Determining the statistical significance of survivorship prediction models. J Eval Clin Pract 2010; 16: 155-65. doi: 10.1111/j.1365-2753.2009.01199.x

37. Mantel N. Evaluation of survival data and two new rank order statistics arising in its consideration. Cancer Chemother Rep 1966; 50: 163-70.

38. International Union Against Cancer. TNM classification of malignant tumours. Sobin LH, Gospodarowicz MK, Wittekind C, editors. 7th Edition Oxford: Wiley-Blackwell; 2011

39. Gorlia T, van den Bent MJ, Hegi ME, Mirimanoff RO, Weller M, Cairncross JG, et al. Nomograms for predicting survival of patients with newly diagnosed glioblastoma: prognostic factor analysis of EORTC and NCIC trial 26981 22981/CE.3. Lancet Oncol 2008; 9: 29-38. doi: http://dx.doi.org/10.1016/ S1470-2045(07)70384-4

40. Khan L, Soliman H, Sahgal A, Perry J, Xu W, Tsao MN. External beam radiation dose escalation for high grade glioma. Cochrane Database Syst Rev 2016; 8: CD011475. doi: 10.1002/14651858.CD011475.pub2

41. Roa W, Kepka L, Kumar N, Sinaika V, Matiello J, Lomidze D, et al. International Atomic Energy Agency randomized phase III study of radiation therapy in elderly and/or frail patients with newly diagnosed glioblastoma multiforme. $J$ Clin Oncol 2015; 33: 4145-50. doi: 10.1200/JCO.2015.62.6606

42. McDonald MW, Shu H-KG, Curran WJ, Crocker IR. Pattern of failure after limited margin radiotherapy and temozolomide for glioblastoma. Int J Radia Oncol 2011; 79: 130-6. doi: 10.1016/j.jjrobp.2009.10.048

43. Minniti G, Amelio D, Amichetti M, Salvati M, Muni R, Bozzao A, et al Patterns of failure and comparison of different target volume delineations in patients with glioblastoma treated with conformal radiotherapy plus concomitant and adjuvant temozolomide. Radiother Oncol 2010; 97: 377 81. doi: $10.1016 /$ j.radonc. 2010.08 .020

44. Dobelbower MC, Burnett III OL, Nordal RA, Nabors LB, Markert JM, Hyat $M D$, et al. Patterns of failure for glioblastoma multiforme following concurrent radiation and temozolomide. J Med Imaging Radiat Oncol 2011; 55: 77-81. doi: 10.1111/j.1754-9485.2010.02232.x

45. Gebhardt BJ, Dobelbower MC, Ennis WH, Bag AK, Markert JM, Fiveash JB. Patterns of failure for glioblastoma multiforme following limited-margin radiation and concurrent temozolomide. Radiat Oncol 2014; 9: 130. doi: $10.1186 / 1748-717 X-9-130$ 